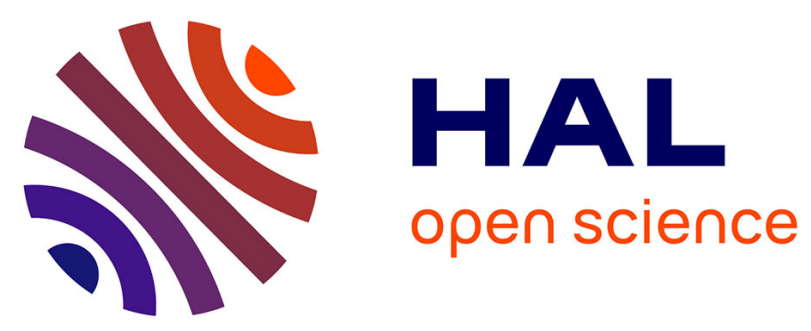

\title{
Impact of Low Sonic Boom Exposure on Psychophysical and Cognitive Performance
}

Frederic Marmel, Claudia Fritz, Léo Cretagne, Linh-Thao Thuong, Carlos Garcia Armijos, François Ollivier, Uwe Muller, François Coulouvrat

\section{- To cite this version:}

Frederic Marmel, Claudia Fritz, Léo Cretagne, Linh-Thao Thuong, Carlos Garcia Armijos, et al.. Impact of Low Sonic Boom Exposure on Psychophysical and Cognitive Performance. eForum Acusticum 2020, Dec 2020, Lyon, France. pp.999-1000, 10.48465/fa.2020.0362 . hal-03229478

\section{HAL Id: hal-03229478 \\ https://hal.science/hal-03229478}

Submitted on 21 May 2021

HAL is a multi-disciplinary open access archive for the deposit and dissemination of scientific research documents, whether they are published or not. The documents may come from teaching and research institutions in France or abroad, or from public or private research centers.
L'archive ouverte pluridisciplinaire $\mathbf{H A L}$, est destinée au dépôt et à la diffusion de documents scientifiques de niveau recherche, publiés ou non, émanant des établissements d'enseignement et de recherche français ou étrangers, des laboratoires publics ou privés. 


\title{
Impact of Low Sonic Boom Exposure on Psychophysical and Cognitive Performance
}

\author{
F. Marmel ${ }^{\mathrm{a}}$, C. Fritz ${ }^{\mathrm{b}}$, L. Cretagne ${ }^{\mathrm{a}}$, L.-T. Thuong ${ }^{\mathrm{a}}$, C. Garcia Armijos ${ }^{\mathrm{a}}$, F. Ollivier ${ }^{\mathrm{c}}$, U. Mueller $^{\mathrm{d}}$ and F. Coulouvrat ${ }^{\mathrm{b}}$ \\ a'Sorbonne Université, Institut Jean Le Rond d'Alembert (UMR 7190), 2 place de la gare de ceinture, 78210 Saint-Cyr L'École, France \\ ${ }^{b}$ CNRS, Institut Jean Le Rond d'Alembert (UMR 7190), Sorbonne Université - 4 place Jussieu, 75005 Paris, France \\ 'Sorbonne Université, Institut Jean Le Rond d'Alembert (UMR 7190), 4 place Jussieu, 75005 Paris, France \\ ${ }^{d}$ Deutsches Zentrum für Luft- und Raumfahrt, Institute for Aerospace Medicine, Linder Höhe, 51147 Köln, Germany \\ frederic.marmel@upmc.fr
}

Rationale \& Objectives: The RegUlation and norM for low sonic Boom Levels (RUMBLE) European project aims to quantify the effects of low sonic boom exposure on human responses in representative situations for European citizens, so as to inform policy, establish standards and develop protection concepts for a new generation of supersonic commercial aircraft that should emit a reduced but perceivable boom (a 'low boom') while flying overland. With this in view, we built a low boom simulator, affixed to the windows of a two-story house, that can reproduce realistic signals inside the house, with or without rattle noise. We used the simulator to conduct a study that evaluated the annoyance caused by low booms, as well as their impact on performance in psychophysical and cognitive tasks. We compared low booms of two different sound levels in three conditions with different degrees of rattle.

\section{Material \& Methods:}

House set-up: The study took place on the ground floor of a two-story house located on a remote campus site. Two low-boom simulators were built and affixed to the outside of the windows of two bedrooms located on opposite sides of the house (the window frames were removed). Participants completed the study in the living room and in the kitchen.

Low-boom simulators: Each simulator was made of 6 subwoofers for low frequencies $(<100 \mathrm{~Hz})$ and 1 loudspeaker for medium and high frequencies, housed in a wood structure with acoustic insulation. The simulators achieved highfidelity reproduction up to $20 \mathrm{~Pa}(75 \mathrm{dBA})$ of amplitude across 2-8000 Hz. For low boom generation, a double spectral (equalization) and temporal (WDT) optimization was performed. Simulators were powered by 6 amplifiers ( 3 per simulator) with a total installed electrical power of $6 \times 800 \mathrm{~W}$.

Participants: 39 participants, aged 18-69 years (18-30yrs: 18, 31-45yrs: 12, 46-60yrs: 6, 61-70yrs: 2). Participants completed the study in pairs (with one exception due to one participant not showing up). Participants signed an informed consent and were compensated for their time. The study was conducted anonymously. The University ethics committee approved the study ( $n^{\circ}$ CER $\left.2020-4\right)$.

\section{Experimental Tasks:}

Memory task ("2-back"): Twenty playing cards were displayed one after another and participants had to constantly compare the card on display to the penultimate card displayed. For each card, participants had to judge whether or not it was the same as the penultimate card displayed. One low boom was presented randomly between the $8^{\text {th }}$ and the $14^{\text {th }}$ card of each 20 -card series. Six series were presented per experimental condition. Percentages of correct responses and response times were collected.

Evaluative priming task: Acoustically-presented sounds were immediately followed by visually-presented words that were either positive or negative. For each "sound-word" pair, participants had to judge as quickly and as correctly as possible whether the word was pleasant or unpleasant. Participants were instructed to ignore the sounds. The sounds were either: one of four known negative sounds, one of four known positive sounds, or one of two low booms. Six positive and six negative words were used, and each possible "sound-word" pair was used once. The order of the "sound-word" pairs was pseudo-randomized. Evaluative priming predicts more correct responses and faster responses for words preceded by a sound of the same valence than words preceded by a sound of the opposite valence. This task aimed to give us an indirect measurement of the low booms' valence.

Questionnaires: After each task, participants answered a questionnaire in order to collect their impressions on the 
task difficulty, the booms, and the rattle.

Experimental Conditions: The 2 back task was performed without booms in the living rooms, and with booms in the living room and in the kitchen. There was more rattle in the kitchen than in the living room because of a flimsy glass door in the kitchen. In both rooms, the task was performed once with the low boom set to $62 \mathrm{dBA}$ and once with the low boom set to $75 \mathrm{dBA}$ (at the simulator's output). The evaluative priming task was only performed in the living room.

Results: Data analysis has just started at the time of writing and all results are preliminary partial results.

2back task: Data for the four boom conditions have been concatenated to increase power. Cards have been renumbered within each series so that the card that was on display when the boom occurred was always card $n^{\circ} 0$. Figure 1 shows the response times for correct responses (mean \pm sem): responses took longer for the card on display when the boom occurred and for the two following cards.

Evaluative priming task: Contrary to our prediction, no priming effect was observed, nor for negative sounds, positive sounds or booms. Plotting response times with negative and positive words collapsed, for each sound, reveals that participants took longer to judge the words for the booms than for the other sounds (Figure 2).

Questionnaires: Questionnaires for the two sessions of the 2back task done in the kitchen were collapsed and compared to the two sessions done in the living room (Figure 3): the task seemed a bit more difficult and the booms a bit more annoying/disturbing in the living room than in the kitchen. Comparing the questionnaires for the two sessions of the task done with lower-level booms to the two done with higher-level booms showed no difference.

Figure 1

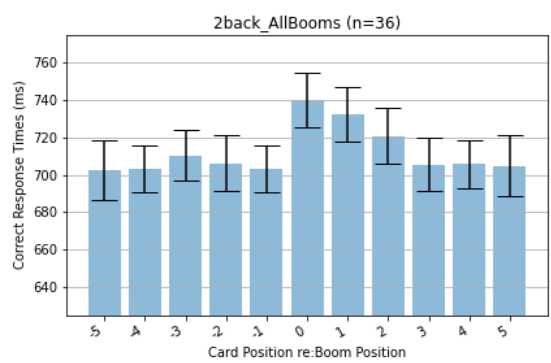

Figure 2

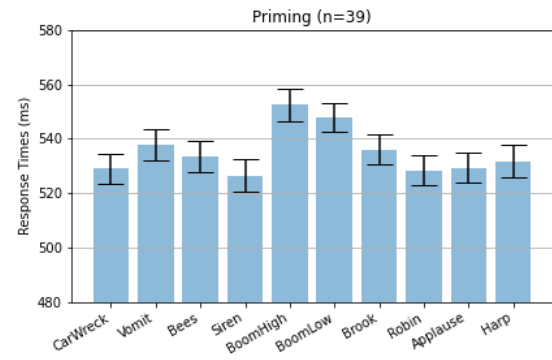

Figure 3

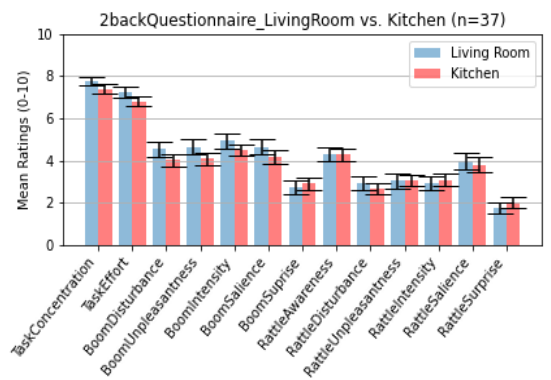

\section{Discussion:}

2back task: The booms seems to disturb the process of retaining cards in memory and storing new cards as responses were longer for the first three cards seen from the boom onset. The respective influences of the boom level and of the rattle remain to be analyzed.

Evaluative priming task: We failed to replicate an evaluate priming effect even though we used established positive and negative sounds previously used to show a priming effect (Scherer \& Larsen, 2011, Emotion, DOI:

10.1037/a0022588). One explanation might be that we used short sounds ( 2 seconds) in order to roughly match the perceived duration of the boom. However, we observed, as for the 2back task, that the booms disturb task completion (longer response times).

Questionnaires: The slight difference observed was contrary to expectations: we expected the greater degree of rattle in the kitchen to result in the booms being judged more annoying/disturbing in the kitchen than in the living room. The lack of difference between the two sound levels was also a surprise.

Much more data analysis remains to be done: potential order effects should be investigated, even though the order of conditions was pseudo-randomized. Conditions should be analyzed separately and compared. Task performance and questionnaires should be compared within individuals.

Acknowledgments: This research was conducted as a part of Rumble - EU Grant Agreement 769896. 